\title{
HIV Epidemiology in Uganda: survey based on age, gender, number of sexual partners and frequency of testing
}

\author{
Jay Vithalani ${ }^{1}$, Marta Herreros-Villanueva ${ }^{2}$
}

1. American University of Antigua College of Medicine - New York.

2. Universidad del País Vasco UPV/EHU, Department of Gastroenterology; Universidad Isabel I.

\begin{abstract}
:
Background:Human Immunodeficiency Virus (HIV) is a major cause of morbidity and mortality in the world. When compared to the developed countries where HIV prevalence is on the decline, sub-Saharan Africa has experienced either a rise or stagnation in rates.

Objectives: The aim of this study was to test and educate the community in the villages of Masajja and Kibiri of Wakiso district in Uganda for HIV and safe sex practices.

Methods: A sociodemographic survey was also performed to obtain data for gender, age, number of sexual partners during the previous year, frequency of testing and if ever tested positive for other sexually transmitted diseases (STDs).

Results: While 7 of the tested individuals were positive for HIV, 77 reported that they had once tested positive for other STDs. Of the $7 \mathrm{HIV}$ positive individuals, 4 were females and 3 males. Over half of the tested individuals reported only one sexual partner in past 12 months and more than a quarter were sexually active with more than one partner. Majority of our population also reported getting HIV tested every 6 months or less.

Conclusion: Robust implementation of methods such as education and frequent testing can lower Uganda's prevalence of HIV even further.

Keywords: HIV Epidemiology, age, gender, number of sexual partners, frequency of testing, Uganda.

DOI: https://dx.doi.org/10.4314/ahs.v18i3.8

Cite as: Vithalani J, Herreros-Villanueva M. HIV Epidemiology in Uganda: Survey based on age, gender, number of sexual partners and frequency of testing. Afri Health Sci. 2018;18(3): 523-530. https:/ / dx.doi.org/10.4314/ahs.v18i3.8
\end{abstract}

\section{Introduction}

Human Immunodeficiency Virus (HIV) is without a doubt one of the most serious conditions affecting the human population in the $21^{\text {st }}$ century $\left.{ }^{1}\right)$. According to the recent late 2016 statistics from World Health Organization (WHO), 36.7 million people worldwide are currently living with $\mathrm{HIV}^{1,2}$. Of all the regions, one of the most heavily affected is sub-Saharan Africa where approximately 1 in every 25 adults (>18 years old) is currently living with HIV, accounting for roughly two thirds of all individuals currently living with HIV worldwide ${ }^{1}$.

\section{Corresponding author:}

Jay Vithalani, American University of Antigua - New York. Email: jayv@auamed.net
Investigations into HIV began in 1981 due to an increase in the rates of a rare lung infection amongst young and homosexual men, confirmed cases of Pneumocystis carinii pneumonia (PCP). PCP is a serious complication in individuals with impaired immune system, such as acquired HIV patients ${ }^{3}$.

Adquired Immunodeficiency Syndrome (AIDS) is the disease caused by infection with HIV and is characterized by profound immuno-suppression with associated opportunistic infections, malignant tumors, wasting and central nervous system degeneration.

It is well known that HIV infection leads to dysfunction of both the adaptive and innate immune systems, affecting mainly the cell-mediated immunity because of the depletion of $\mathrm{CD}^{+} \mathrm{T}$ cells, due to several mechanisms, including direct cytopathic effects of the virus and indirect effects. Additionally, it leads to functional defects in

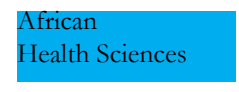

(C) 2018 Vithalani et al. Licensee African Health Sciences. This is an Open Access article distributed under the terms of the Creative commons Attribution License (https://creativecommons.org/licenses/BY/4.0), which permits unrestricted use, distribution, and reproduction in any medium, provided the original work is properly cited. 
the immune system that increase the immune deficiency caused by $\mathrm{CD}^{+}{ }^{+} \mathrm{T}$ depletion.

$\mathrm{HIV}$-induced depletion and functional defects of $\mathrm{CD}^{+}$

$\mathrm{T}$ cells results in increased susceptibility to infection by a number of opportunistic micro-organisms, such as Pneumocystis.

$\mathrm{HIV}$ infects not only $\mathrm{CD}^{+}{ }^{+}$helper $\mathrm{T}$ cells, but also macrophages, and dendritic cells, contributing to the progression of immunodeficiency ${ }^{4}$.

As the number of HIV cases increased, an epidemic was announced in 1984, when the National Cancer Institute announced the cause of HIV, the retrovirus HTLVIII leading to Acquired Immune Deficiency Syndrome $(\text { AIDS })^{5}$. This has since become a worldwide pandemic with over 2 million newly infected individuals in 2015, including 150,000 children ( $<15$ years old $)^{2}$. Of the high rates of HIV infections in Sub-Saharan Africa, the country of Uganda is of a particular interest. During the period of 2005 and 2013, the number of new HIV infections in Uganda increased by $10 \% 0^{6}$. According to recent UNAIDS data, approximately 570 young women aged 15 to 24 get infected with HIV every week in Uganda. In all of Africa, Uganda is only second to South Africa where 2,363 individuals get infected every week. In 2013, Uganda combined with Nigeria and South Africa accounted for almost $48 \%$ of all the new HIV cases in sub-Saharan Africa $^{6,7}$.

Uganda is a landlocked country with a 2014 reported population of 34.8 million people 8 . It lies within the Nile basin and shares its borders with Kenya, South Sudan, Democratic Republic of Congo, Rwanda and Tanzania, and it is divided into four regions: Northern, Central, Eastern and Western. The first case of HIV (AIDS - Slim disease) in Uganda was reported in 1982 in Kansensero, a fishing village located in the Western region'. Currently, HIV prevalence is highest in the Central region $(10.4 \%)$ due to its urbanization and location of the capital city Kampala - home to 1.5 million people according to 2014 statistics $^{8}$. Of the key populations, highest prevalence rates exist among sex workers (35-37\%), fishermen $(22-29 \%)$, truck drivers $(25 \%)$ and homosexual men $(13.7 \%)^{10,11}$.
Cultural and political barriers combined with laws directed towards the punishment and stigmatization of sex workers and homosexuality are at the roots of high HIV prevalence in Uganda. In 2013, the parliament of the country passed "The Uganda Anti-Homosexuality Act" leading to an increase in the harassment and prosecution ${ }^{12}$. In 2014, it was estimated that $16 \%$ of all previously mentioned new HIV infections were caused by sex workers and their clients. Refusal to use sexual protection remained a number one cause for such a high number. According to data obtained from 2015 Global AIDS Response Progress Reporting (GARPR), only $69.4 \%$ of female sex workers admitted to using condoms during sexual activity ${ }^{13}$. Other factors of high prevalence amongst young females also include lack of sexual education, access to health services and social protection ${ }^{7}$.

Despite this data, Uganda is one of only few countries in the world that has managed to reverse its HIV epidemic. With reported prevalence rates of $18-30 \%$ in the 1990 s, Uganda was one of the highest in the world. Late 2000s statistics showed a drastically decreased prevalence rate hovering around $6.5 \% \%^{2}$. However, reports in 2012 suggested that Uganda was one of only two African countries where rates of new HIV infections were back on the rise. This resulted in an increased prevalence rate of up to $7.3 \%{ }^{14}$. Health experts believe that the government's complacency and stagnant actions may be to blame for this rise ${ }^{6}$. The President of Uganda has since then renewed commitment to decrease the prevalence further by encouraging people to know their HIV status and to seek early treatment and counseling. Latest reports from 2016 display that the prevalence rate has now decreased to $6.5 \%{ }^{2}$. Uganda's strong approach which differed from world approach of mainly barrier protection may have led to this decrease ${ }^{15}$.

Still, approximately $60 \%$ of individuals infected with HIV are unaware of their infection ${ }^{6}$. Stigma of testing positive only discriminates further into people not getting tested. However, frequent testing has been proven to raise awareness and has led to a decrease in condom-less sexual behavior. Approximately 5.1 million individuals 
were tested under this service in 2011. This number has since increased to 9.5 million in 2014 - nearly double in just 3 years. Additional programs include assistance from UNAIDS and other organizations which tackle motherto-child HIV transmission, voluntary medical male circumcision, sexual protection education and increasing the accessibility of anti-retroviral therapy ${ }^{6}$.

Frequent HIV testing is at the heart of preventing new infections. Knowledge of an individual's HIV status assists in education about safe sex practices and encourages in seeking early treatment should a result become positive. The Government of Uganda has also launched several campaigns that encourage the use of community outreach with the help of local and international volunteer organizations. With the help of government and donating organizations, more and more local clinics and medical centers are now armed with free supplies of condoms and economical forms of testing ${ }^{8,14}$.

This study was conducted in the villages of Masajja and Kibiri of Wakiso district in Uganda. The aim of this study was to test and counsel a population for HIV status and gather data regarding frequency of testing and number of sexual partners amongst different age groups. The study also looked at whether the tested population had ever tested positive for any other STDs such as Chlamydia, Gonorrhea, Herpes Simplex Virus or Syphilis.

\section{Subjects and methods}

Investigations for this study were performed in August 2017 at Alexas Medical Center in Masajja and Kibiri. A total of 442 individuals 14 years of age and older were tested for HIV using blood samples. The inclusion criteria included both genders and individuals with unknown or negative HIV serostatus at the time of testing. Signed informed consent forms were obtained from adults $(>18$ years old) and mother/father's signed consent was obtained for individuals younger than the age of 18. Eligible individuals were invited for participation in an interview conducted in local language of Luganda or English for data collection. Socio-demographic data was collected through a structured questionnaire that included gender, age, number of sexual partners in the past 12 months, frequency of testing and if ever tested positive for other

African Health Sciences Vol 18 Issue 3, September, 2018 sexually transmitted diseases (STDs) such as Chlamydia, Gonorrbea, Herpes Simplex Virus or Syphilis.

HIV testing was performed according to Uganda Ministry of Health's Clinical Guidelines released in 2016 ${ }^{16}$. Participants were tested using Alere Determine ${ }^{\mathrm{TM}}$ HIV 1/2 $\mathrm{Ag} / \mathrm{Ab}$ (Alere, Ref.7D2343) and Chase Buffer (Alere, Ref. 7D2243) for HIV with peripheral whole blood samples. Alere Determine ${ }^{\mathrm{TM}} \mathrm{HIV} 1 / 2 \mathrm{Ag} / \mathrm{Ab}$ is a reliable rapid point-of-care test that detects both $\mathrm{HIV}-1 / 2$ antibodies and the HIV-1 antigen, which can appear approximately 12-26 days after infection. Results of the test were obtained after 15-60 minutes as standard procedure. Alere Determine $^{\mathrm{TM}}$ is a highly reliable test with a sensitivity of $100 \%$ and specificity of $99.68 \%$. Individuals with positive test results were confirmed using HIV1/2 Stat-Pak Dipstick Assay (Chembio, Ref. HIV303) which possesses a sensitivity/specificity of $99-100 / 100 \%$. Confirmed positive individuals were informed and counseled onsite and referred to community hospitals closest to their place of living for further testing and treatment.

The data analysis relied on Microsoft Excel version 3.04, using the new fancier's database. Obtained results were characterized into age groups, numbers of partners in the last 12 months and frequency of testing. Ages were grouped as 14-17 years, 18-30 years, 31-40 years, 41-50 years, and $>51$ years old. Numbers of partners in the past 12 months were grouped as $0,1,2,3,4,5$ and $>5$. Frequency of testing was grouped as never tested before, every 0-3 months, every 4-6 months, every 7-12 months, and $>12$ months ago.

\section{Results}

Out of 442, 220 were females and 222 males. The data for number of individuals tested and differentiated into different age groups and gender is shown in Table I. Different age groups were established based on 10-13 years intervals. However, an initial range of $14-17$ was also included since 27 participants were under 18. A group of 18-30 was included since 18 is the age at which people in majority of countries reach adulthood. Moreover, this age range (18-30) includes most of sexually active participants. Majority of the individuals tested fell within the range of 18-30 years of age. Of the individuals tested, 7 $(1.6 \%)$ were found to be positive following Government of Uganda's two tier testing guidelines. 
Table I. Total number of participants differentiated into age and gender.

\begin{tabular}{|c|c|c|c|}
\hline $\begin{array}{c}\text { Age } \\
\text { (Years) }\end{array}$ & Male & Female & Total \\
\hline $\mathbf{1 4 - 1 7}$ & 9 & 18 & 27 \\
\hline $\mathbf{1 8 - 3 0}$ & 154 & 155 & 309 \\
\hline $\mathbf{3 1 - 4 0}$ & 44 & 40 & 84 \\
\hline $\mathbf{4 1 - 5 0}$ & 13 & 5 & 18 \\
\hline $\mathbf{2 5 1}$ & 2 & 2 & 4 \\
\hline Total & 222 & 220 & 442 \\
\hline
\end{tabular}

Table II shows that 4 out of 7 positive results were between the ages of 18-30 and 3 between the ages of 31-40. Furthermore, 4 out of 7 positive results were females and 3 males.
Data from the questionnaire of whether any of the tested individuals were ever tested positive for other STDs such as Chlamydia, Gonorrhea, Syphilis or HSV as shown in Table III.

Table II. Results of the HIV test differentiated into age groups.

\begin{tabular}{|c|c|c|c|}
\hline $\begin{array}{c}\text { Age } \\
\text { (Years) }\end{array}$ & Positive & Negative & Total \\
\hline $\mathbf{1 4 - 1 7}$ & 0 & 27 & 27 \\
\hline $\mathbf{1 8 - 3 0}$ & 4 & 305 & 309 \\
\hline $\mathbf{3 1 - 4 0}$ & 3 & 81 & 84 \\
\hline $\mathbf{4 1 - 5 0}$ & 0 & 18 & 18 \\
\hline $\mathbf{5 1}$ & 0 & 4 & 4 \\
\hline Total & 7 & 435 & 442 \\
\hline
\end{tabular}

Table III. Number of individuals admitted to once tested positive for other STDs classified into different age groups.

\begin{tabular}{|c|c|c|}
\hline $\begin{array}{c}\text { Age } \\
\text { (Years) }\end{array}$ & HIV+ & Other STD + \\
\hline $\mathbf{1 4 - 1 7}$ & 0 & 0 \\
\hline $\mathbf{1 8 - 3 0}$ & 4 & 64 \\
\hline $\mathbf{3 1 - 4 0}$ & 3 & 12 \\
\hline $\mathbf{4 1 - 5 0}$ & 0 & 0 \\
\hline $\mathbf{5 5 1}$ & 0 & 1 \\
\hline Total & 7 & 77 \\
\hline
\end{tabular}

STDs = Sexually Transmitted Diseases 
This result is also categorized into different age groups. As it can be seen, while only 7 individuals tested positive for HIV, 77 reported that they had once tested positive for other STDs. Table IV displays the number of sexual partners that the tested individuals have been with in past 12 months. Very importantly, while over half reported to having only one sexual partner in past 12 months, more than a quarter of the population engaged in sexual activity with more than one partner. Few individuals also reported 4 to 5 sexual partners in the previous year. As represented in Table V, where frequency of HIV testing show that the majority of these individuals fall between the categories of 4-6 months and 7-12 months.

Table IV. Number of sexual partners in past 12 months differentiated among age groups.

\begin{tabular}{|c|c|c|c|c|c|c|}
\hline & \multicolumn{7}{|c|}{ AGE (YEARS) } & \\
\hline $\begin{array}{c}\text { \# of partners } \\
\text { (Past 12 months) }\end{array}$ & $\mathbf{1 4 - 1 7}$ & $\mathbf{1 8 - 3 0}$ & $\mathbf{3 1 - 4 0}$ & $\mathbf{4 1 - 5 0}$ & $\mathbf{> 5 1}$ & TOTAL \\
\hline $\mathbf{0}$ & 12 & $\mathbf{2 9}$ & 8 & $\mathbf{2}$ & 2 & 53 \\
\hline $\mathbf{1}$ & 11 & 186 & 56 & 12 & 1 & 266 \\
\hline $\mathbf{2}$ & 1 & 50 & 14 & 2 & 0 & 67 \\
\hline $\mathbf{3}$ & 1 & 16 & 2 & 1 & 1 & 21 \\
\hline $\mathbf{4}$ & 1 & 8 & 2 & 0 & 0 & 11 \\
\hline $\mathbf{5}$ & 1 & 13 & 1 & 1 & 0 & 16 \\
\hline $\mathbf{> 5}$ & 0 & 7 & 1 & 0 & 0 & 8 \\
\hline TOTAL & 27 & 309 & 84 & 18 & 4 & 442 \\
\hline
\end{tabular}

Table V. Frequency of HIV testing differentiated among age groups.

\begin{tabular}{|c|c|c|c|c|c|c|}
\hline & \multicolumn{5}{|c|}{ AGE (YEARS) } & \\
\hline $\begin{array}{c}\text { Frequency of } \\
\text { testing }\end{array}$ & $\mathbf{1 4 - 1 7}$ & $\mathbf{1 8 - 3 0}$ & $\mathbf{3 1 - 4 0}$ & $\mathbf{4 1 - 5 0}$ & $\mathbf{> 5 1}$ & Total \\
\hline Never tested & 14 & 41 & 5 & 0 & 0 & 60 \\
\hline $\mathbf{0 - 3}$ months & 3 & 73 & 23 & 4 & 0 & 103 \\
\hline $\mathbf{4 - 6}$ months & 5 & 92 & 25 & 4 & 1 & 127 \\
\hline $\mathbf{7 - 1 2}$ months & 4 & 84 & 23 & 5 & 1 & 117 \\
\hline$>\mathbf{1 2}$ months & 1 & 19 & 8 & 5 & 2 & 35 \\
\hline Total & 27 & 309 & 84 & 18 & 4 & 442 \\
\hline
\end{tabular}




\section{Discussion}

In this population of 442 individuals, 222 were male and 220 were female. Equal ratio of people wanting to be tested suggested that both genders were equally curious regarding their HIV status. Of the total of 442 individuals, 7 people were positive for HIV - 4 females and 3 males.

We are conscious of our limitation in this study- the reduced number of tested individuals. However, our data are representative of reality in Uganda and confirm previous published data. Gender distribution result is expected as reports show that in sub-Saharan Africa, females are more prone to being positive than males ${ }^{17,18}$. Our results confirmed, as previously indicated in other studies that women continue to bear the brunt of the epidemic, with young women infected more frequently when compared to their male counterparts. The combination of social, economic and biological factors are a few reasons for such reports. Social factors such as gender based abuse and violence make women more prone to becoming infected. Lack of economic ability may lead to trading of education about HIV and women's rights for basic survival. Biological factors such as the female reproductive anatomy can put women at even more risk of contracting HIV. One of the reports suggests that younger women are more prone to HIV infection due to an immature opening of cervix which lacks the thickness and thus purpose of acting as a barrier to an incredibly vascular uterus $^{17}$.

Of the 7 positive results, 4 individuals were between the ages of 18-30 years and 3 between 31-40, prime ages for sexual activity. Risky sexual behavior is one of the main risk factors for a person becoming infected with $\mathrm{HIV}^{6,7}$. This is also one of the risk factors for testing positive for other sexually transmitted diseases such as Chlamydia, Gonorrhea, Syphilis and HSV. While being positive for a few of these diseases can be easily curable or manageable, HIV is more difficult to treat. Treatment for HIV can be a financial burden for anyone, especially for individuals from under-developed countries. According to Centers for Disease Control and Prevention in the USA, people who become positive for these STDs are also more likely to test HIV positive in the future ${ }^{18}$. Younger Individuals are especially at risk due to engagement in high risk sexual behaviors. Of the 309 people tested between the ages of
18-30, 64 reported previously testing positive for at least one of the other listed STDs.

Number of sexual partners also has a clear association with being at risk for HIV. Mah et al. ${ }^{19}$ cites that having more than one partner can increase the size of the HIV epidemic. As more partners become infected, it can also increase the speed at which it infiltrates a population and its persistence within a given population ${ }^{19}$. Table IV displays the number of partners within the chosen age groups amongst the 442 tested individuals in this population. Approximately $28 \%$ of the population reported being sexually active with more than 1 partner in the past 12 months. This number is concerning due to its association with increased risk of contracting not only HIV infection but other STDs as well. Table IV also differentiates this number into different age groups and the data clearly shows that majority of individuals engaging in sexual activity with more than one sexual partners fall into the age category of 18-30 years old, the age at most risk for HIV infection.

In countries such as Uganda where the prevalence rate of $\mathrm{HIV}$ is comparatively high, frequent testing is a great resource to raise awareness. Studies have proven that knowing one's HIV status improves awareness and education which leads to a decrease in risky sexual behavior ${ }^{21}$. As covered earlier, government and several international organizations are doing their part to raise awareness through television advertisements, and roadside billboards. The data presented in Table $\mathrm{V}$ shows that it may be successful. According to our survey, only 35 (7.9\%) out of 442 individuals tested greater than 12 months ago and more than half tested between 0-6 months. Important to note that in our cohort, $347(78.5 \%)$ of individuals admitted to testing in a timeframe of one year while only 60 (13.6\%) had never been tested before. Frequent testing and counseling is at the heart of preventing new HIV infections. Knowledge of one's HIV status can also lead to seeking of early treatment before $\mathrm{CD}^{+}{ }^{+}$count becomes drastically low ${ }^{22}$.

\section{Conclusion}

From the beginning of the AIDS epidemic in the 1980s, Uganda's overall prevalence rate has been on a downward track. The government and people of Uganda have prov- 
en that it is possible to decrease the prevalence rate from as high as $18-30 \%$ to $6.5 \% \%^{6,12}$. A lot of this success can be credited to past efforts of raising awareness and laying down the ground work for HIV education. However, efforts may be becoming stagnant. A steady level of 6.5\% is still much higher when compared to that of the developed nations ${ }^{23}$. In Uganda, the number of sexual partners per year is concerning especially amongst the younger population because of increased risk of HIV infection. Education about sexual rights can help in decreasing the high prevalence rate amongst younger individuals, especially females ${ }^{6,7}$. Organizations such as the CDC in the United States have shown clear association between contracting STDs and increased risk of HIV infection. Increased awareness regarding condom usage for protection against STDs and HIV can be a great advantage to the community health ${ }^{18}$. Uganda is on the right path to raise awareness about frequent testing for HIV with the help of roadside billboards and television advertisements. Along with urging the public to get tested for HIV status, it also provides education about HIV. Continued efforts such as this combined with the help of world organizations and assistance from the Government of Uganda, the country can be on the path to drastically decrease the rate of new HIV infections in the future.

\section{Funding}

This community outreach and project was funded by the authors.

\section{Competing interests}

None declared.

\section{Contributions}

All authors took part in study design, data collection, data analysis, writing and editing. Final version is approved by all authors.

\section{References}

1. HIV/AIDS: Global health Observatory (GHO) data,World Health Organization, 2017. Available from http://www.who.int/gho/hiv/en/. Accessed October 10, 2017.

2. Collaborators GH. Estimates of global, regional, and national incidence, prevalence, and mortality of HIV, 1980-2015: the Global Burden of Disease Study 2015. Lancet HIV. 2016;3(8): e361-e87. PubMed.
3. Centers for Disease Control and Prevention C. Pneumocystis pneumonia--Los Angeles. MMWR Morb Mortal Wkly Rep. 1981;30(21):250-2.

4. In: Coffin JM, Hughes SH, Varmus HE, editors. Retroviruses. Cold Spring Harbor (NY)1997.

5. Marx JL. Strong new candidate for AIDS agent. Science. 1984;224(4648):475-7. PubMed.

6. Kharsany AB, Karim QA. HIV Infection and AIDS in sub-Saharan Africa: Current Status, Challenges and Opportunities. Open AIDS J. 2016;10:34-48. PubMed.

7. UNAIDS Global Data Book, UNAIDS, 2017. Available from: http://www.unaids.org/sites/default/files/ media_asset/20170720_Data_book_2017_en.pdf. Accessed 20 September, 2017

8. National population and housing census 2014, Republic of Uganda. Uganda Bureau of statistics 2016. http:// library.health.go.ug/publications/leadership-and-governance-monitoring-and-evaluation/population/national-population-an-0

9. Serwadda D, Mugerwa RD, Sewankambo NK, Lwegaba A, Carswell JW, Kirya GB, et al. Slim disease: a new disease in Uganda and its association with HTLV-III infection. Lancet. 1985;2(8460):849-52. PubMed.

10. Kiwanuka N, Ssetaala A, Nalutaaya A, Mpendo J, Wambuzi M, Nanvubya A, et al. High incidence of HIV1 infection in a general population of fishing communities around Lake Victoria, Uganda. PLoS One. 2014;9(5): e94932. PubMed.

11. Uganda AIDS Commission (2008) The Modes of Transmission Study. The Uganda Country Synthesis Report. Kampala, Uganda.

12. Jewkes R, Morrell R. Gender and sexuality: emerging perspectives from the heterosexual epidemic in South Africa and implications for HIV risk and prevention. $J$ Int AIDS Soc. 2010;13:6.

13. HIV risk and prevention. Available from http:// aidsinfo.unaids.org. Accessed 30 October 2017.

14. Ministry of Health $(\mathrm{MoH})$ : Uganda AIDS IndicatorSurvey. Kampala: MoH; 2011. Available from https:// dhsprogram.com/pubs/pdf/AIS10/AIS10.pdf.Accessed 10 October 2017.

15. Green EC, Halperin DT, Nantulya V, Hogle JA. Uganda's HIV prevention success: the role of sexual behavior change and the national response. AIDS Behav. 2006;10(4):335-46; discussion 47-50. PubMed

16. Uganda Ministry of Health. Consolidated Guidelines for Prevention and Treatment of HIV in Uganda. Kampala: Uganda Ministry of Health; 2016. 
17. Yi TJ, Shannon B, Prodger J, McKinnon L, Kaul R. havior change and the national response. AIDS Behav. Genital immunology and HIV susceptibility in young 2006;10(4):335-46; discussion 47-50. PubMed.

women. Am J Reprod Immunol. 2013;69 Suppl 1:74-9.

21. Wood BR, Ballenger C, Stekler JD. Arguments for and 18. Dellar RC, Dlamini S, Karim QA. Adolescent girls and young women: key populations for HIV epidemic control. J Int AIDS Soc. 2015;18(2 Suppl 1):19408. PubMed. 19. Mah TL, Halperin DT. Concurrent sexual partnerships and the HIV epidemics in Africa: evidence to move forward. AIDS Behav. 2010;14(1):11-6; dicussion 34-7. PubMed. against HIV self-testing. HIV AIDS (Auckl). 2014;6:11726.

22. Babiker AG, Emery S, Fatkenheuer G, Gordin FM, Grund B, Lundgren JD, et al. Considerations in the rationale, design and methods of the Strategic Timing of AntiRetroviral Treatment (START) study. Clin Trials. 2013;10(1 Suppl):S5-S36. PubMed.

20. Green EC, Halperin DT, Nantulya V, Hogle JA. 23. Fettig J, Swaminathan M, Murrill CS, Kaplan JE. Uganda's HIV prevention success: the role of sexual be- Global epidemiology of HIV. Infect Dis Clin North Am. 2014;28(3):323-37. 